\title{
Primary Biliary Cirrhosis Associated with Systemic Sclerosis: Diagnostic and Clinical Challenges
}

\author{
Cristina Rigamonti, ${ }^{1}$ Dimitrios P. Bogdanos, ${ }^{2}$ Maria G. Mytilinaiou, ${ }^{2}$ Daniel S. Smyk, ${ }^{2}$ \\ Eirini I. Rigopoulou, ${ }^{3}$ and Andrew K. Burroughs ${ }^{4}$ \\ ${ }^{1}$ Department of Clinical and Experimental Medicine, Università del Piemonte Orientale "A. Avogadro", 28100 Novara, Italy \\ ${ }^{2}$ Institute of Liver Studies, King's College London School of Medicine at King's College Hospital, Denmark Hill Campus, \\ London SE5 9RS, UK \\ ${ }^{3}$ Department of Medicine, University of Thessaly Medical School, Mezourlo, 41110 Larissa, Greece \\ ${ }^{4}$ The Sheila Sherlock Liver Centre and University Department of Surgery, Royal Free Hospital, London NW3 2QG, UK
}

Correspondence should be addressed to Dimitrios P. Bogdanos, dimitrios.bogdanos@kcl.ac.uk

Received 3 June 2011; Accepted 7 September 2011

Academic Editor: Laura K. Hummers

Copyright (C) 2011 Cristina Rigamonti et al. This is an open access article distributed under the Creative Commons Attribution License, which permits unrestricted use, distribution, and reproduction in any medium, provided the original work is properly cited.

\begin{abstract}
Patients with primary biliary cirrhosis (PBC) often have concurrent limited systemic sclerosis (SSc). Conversely, up to onefourth of SSc patients are positive for PBC-specific antimitochondrial antibodies (AMA). The mechanisms responsible for the co-occurrence of these diseases are largely unknown. Genetic, epigenetic, environmental, and infectious factors appear to be important for the pathogenesis of the disease, but the hierarchy of events are not well defined. Patients with SSc and PBC have an increased morbidity and mortality compared with the general population, but whether the presence of both diseases in an affected individual worsens the prognosis and/or outcome of either disease is not clear. Some case reports suggested that the presence of SSc in PBC patents is associated with a more favorable prognosis of the liver disease, whereas others report an increased mortality in patients with PBC and SSc compared to patients with PBC alone. This paper discusses the features of patients with PBCassociated SSc. Our aims are to clarify some of the pathogenetic, diagnostic, and clinical challenges that are currently faced in the routine management of these patients. We also intend to provide some practical hints for practitioners that will assist in the early identification of patients with PBC-associated SSc.
\end{abstract}

\section{Introduction}

1.1. Primary Biliary Cirrhosis. Primary biliary cirrhosis $(\mathrm{PBC})$ is a chronic cholestatic liver disease characterized by immune-mediated chronic nonsuppurative cholangitis that mainly affects interlobular and septal bile ducts [1-3]. PBC is a rare disease with prevalence ranging from 28 to 402 per million [4], which is highly variable based on geographical location. PBC primarily affects middle aged women [5]. Several reports indicate that the incidence and prevalence of $\mathrm{PBC}$ is increasing in the UK, USA, Finland, and Australia [47]. $\mathrm{PBC}$ often occurs in association with other autoimmune conditions [1-3]. The serological hallmark of $\mathrm{PBC}$ is the presence of high-titre serum antimitochondrial autoantibodies (AMA), usually existing in $90-95 \%$ of patients with
PBC [1-3, 8-16]. The presence of AMA in asymptomatic patients is usually indicative of eventual $\mathrm{PBC}$ development [17]. These autoantibodies specifically recognize lipoylated domains within components of the 2-oxoacid dehydrogenase family of enzymes, particularly the E2 component of the pyruvate dehydrogenase complex, located within the inner mitochondrial membrane [1-3, 8-12]. Indirect immunofluorescence using rodent liver, kidney, and stomach sections as substrate is still the most widely used screening assay for AMA in the routine setting [18]. Other techniques such as immunoblotting and ELISA have a higher sensitivity, and the use of cloned mitochondrial antigens and bead assay testing systems allows for the identification of AMA in the sera of patients previously defined as AMA negative [19]. Additionally, PBC-specific antinuclear autoantibodies 
(ANAs) can be observed in 30\% of patients presenting with multiple nuclear dot (antibodies against Sp100) or nuclear membrane staining patterns (antibodies against gp210) [9, $10,12,14,20]$, which are preferentially identified using HEp2 cells as substrate [21]. The autoimmune nature of $\mathrm{PBC}$ is supported by a plethora of experimental and clinical data, such as the presence of autoreactive $\mathrm{T}$ cells and serum autoantibodies in patients with $\mathrm{PBC}[8,15,22-31]$.

The aetiology of $\mathrm{PBC}$ remains unknown, although evidence suggests a role for both genetic susceptibility and environmental factors that remain to be characterized. In fact, a number of chemicals and infectious agents have been proposed to induce the disease in predisposed individuals [22-27, 30, 32-38]. At presentation, patients with PBC may have nonspecific symptoms such as pruritus and fatigue while jaundice is less frequently seen [1-3]. Portal hypertension and its complications may also develop in patients with early, pre-cirrhotic PBC [1-3]. However, the majority of $\mathrm{PBC}$ patients are asymptomatic and diagnosed incidentally during the diagnostic workup or treatment for other conditions $[39,40]$. Currently, a definite diagnosis of $\mathrm{PBC}$ is made on a combination of abnormal serum enzymes indicating cholestasis (i.e., elevated alkaline phosphatase for at least six months), the presence of serum AMA (titre $>1: 40$ by indirect immunofluorescence), and characteristic liver histology with florid bile duct lesions $[1-3,18]$. A probable diagnosis is made when two out of these three criteria are present. Serum AMAs (or disease-specific antinuclear antibodies) may precede disease onset by several years, and many individuals found positive for these autoantibodies in the absence of other criteria eventually develop PBC [17].

$\mathrm{PBC}$ has a progressive course which may extend over many decades, with greatly variable progression rates among patients. The end of this progression is characterised by cirrhosis, liver failure. However, the patterns of clinical disease and natural history have changed significantly in the last two decades after the introduction of medical treatment with ursodeoxycholic acid (UDCA). When UDCA is administered in early $\mathrm{PBC}$ at adequate doses (13$15 \mathrm{mg} / \mathrm{kg} / \mathrm{day}$ ), the progression of the disease is altered, with many patients having a normal life expectancy without additional therapeutic measures [41].

Concomitant autoimmune diseases are often found in patients with $\mathrm{PBC}$. PBC is found in patients with systemic sclerosis (SSc). Also, SSc is one of the most frequent autoimmune rheumatological conditions associated with PBC. This paper discusses the major characteristics of patients with PBC and SSc, and provides clues related to their immunopathogenic link (Table 1).

\section{PBC-SSc}

2.1. Epidemiology. PBC has been considered as the most common liver disorder in patients with systemic sclerosis (SSc) [42]. This association was first described to co-occur by Milbradt in 1934, and it has been noted historically in several case reports. One such case from 1964 reports two patients with SSc and possible (but unconfirmed) PBC [43].
Murray-Lyon et al. report two cases of SSc and PBC [44]. The first case was that of a 64-year-old female with Raynauds and scleroderma of the right hand and arm, who was found to have hepatosplenomegaly [44]. She was positive for AMA, and a liver biopsy confirmed the diagnosis of PBC [44]. The second case was similar, with AMA positivity and PBC confirmed on liver biopsy [44]. Despite several similar reports over the years, liver disease has not been considered a significant feature of scleroderma, and a higher prevalence of liver disease was found in the control populations of several large studies $[45,46]$. The association of lcSSc and PBC was first described in 1970 with two cases of PBC and limited scleroderma [44]. A further six cases were reported by Reynolds et al. [47], and several other case reports have found an association between lcSSc and PBC. The first case reporting an association of $\mathrm{PBC}$ and scleroderma, without features of lcSSc, was described in 1972 [48]. The prevalence of clinically evident PBC among patients with SSc was recently reported to be $2.5 \%$ in a registry of $1700 \mathrm{SSc}$ patients [49] and 2\% in a series of 817 patients with SSc [50]. On the other hand, the prevalence of SSc in patients with PBC is estimated to be around $8 \%$, as demonstrated by two studies comprising large cohorts of patients with $\mathrm{PBC}[49,51]$. However, case reports $[44,47,48,52-63]$ and some series reported a wider range of prevalence $(3-50 \%)$ of SSc, mostly lcSSc, in PBC patients $[42,49,51,55,61,64,65]$.

Large epidemiological studies on PBC note a minority of patients who also have SSc (scleroderma). A large French study found scleroderma in $1 \%$ of a cohort of PBC patients, although $1 \%$ of their first-degree relatives and $1 \%$ of controls were also noted to have scleroderma [66]. One of the most comprehensive epidemiological studies by Gershwin and colleagues found that $2 \%$ of PBC patients and $1 \%$ of their first-degree relatives had scleroderma, compared to none of the controls [39]. First-degree relatives with scleroderma were more often sisters, followed by daughters of PBC patients $[39,67]$. Twin studies in both conditions are scarce. One twin study for SSc found a low concordance of $4.2 \%$ among monozygotic (MZ) twins, compared to $5.6 \%$ in dizygotic (DZ) twins [68]. Interestingly, there was a $90 \%$ concordance for ANA among MZ twins, compared to only $40 \%$ among DZ [68]. A higher concordance of $63 \%$ among $\mathrm{MZ}$ twins was found in the only comprehensive twin study in PBC [69]. Although both twin studies note co-existing autoimmune disease, which was often the same condition in the twin, none have noted SSc in twins with PBC or PBC in twins with SSc.

2.2. Immunopathogenesis. Despite the scarcity of case reports and large-scale studies, the association of PBC and scleroderma seems to be more than coincidental and suggests that these two diseases might have a common autoimmune basis. However, the autoimmune mechanisms behind the PBC-SSc association are still not fully understood. It has been reported that this patient group has clonally expanded CD8(+) T cells expressing one T-cell receptor beta-chain variable region, TCRBV3, which may be involved in the disease pathogenesis [70]. Genetic, epigenetic, environmental, and infectious 
TABLE 1: Features demographic, immunological and genetic features of primary biliary cirrhosis (PBC) and systemic sclerosis (SSc).

\begin{tabular}{|c|c|c|}
\hline & $\mathrm{PBC}$ & SSc \\
\hline Prevalence (highly variable geographically) & 28-402/million & 50-200/million \\
\hline Incidence (highly variable geographically) & 2.3-27/million & $0.6-122 /$ million \\
\hline Male to female ratio & $1: 8$ & $1: 1.5-12$ (highly variable geographically) \\
\hline Peak frequency age & 53 years & $45-64$ years \\
\hline \multirow{2}{*}{ Autoantibodies } & \multirow{2}{*}{ AMA, ANA } & $\begin{array}{l}\text { Limited disease: ACA, anti-Th/To, } \\
\text { anti-U1-RNP }\end{array}$ \\
\hline & & $\begin{array}{l}\text { Diffuse disease: TOPO, anti-RNA polymerase } \\
\text { III, anti-U3-RNP }\end{array}$ \\
\hline \multirow[b]{2}{*}{ Genes (positive associations) } & HLA: DRB1, DQA1, DQB1, DQA2 & $\begin{array}{l}\text { HLA: HLA-DRB1*1104, DQA } 1 * 0501, \\
\text { DQB1*0301, HLA-DRB1*0804, DQA } 1 * 0501 \text {, } \\
\text { DQB }{ }^{*} 0301\end{array}$ \\
\hline & $\begin{array}{l}\text { Non-HLA: IRF5, STAT4, SPIB, } \\
\text { IKZF3-ORMDL3, IL12A, IL12RB, MMEL1, } \\
\text { DENND1B, CD80, IL7, CXCR5, } \\
\text { TNFRSF1A, CLEC16A, NKFB1 }\end{array}$ & $\begin{array}{l}\text { Non-HLA: STAT4, IRF5, BANK1, TNSF4, } \\
\text { TBX21, IL-23R, and C8orf13-BLK }\end{array}$ \\
\hline
\end{tabular}

AMA, anti-mitochondrial antibody; ANA, anti-nuclear antibody; ACA, anti-centromere antibody.

factors appear to be important for the induction of the underlying autoimmune pathology, but the hierarchy of events and the close interplay of these factors are not well defined.

The association between PBC and SSc has been largely based on reports indicating the presence of autoantibodies related to SSc in patients with $\mathrm{PBC}$ and vice versa. Autoantibodies which characterize limited cutaneous SSc (lcSSC) include anti-centromere antibodies (ACA), anti-Th/To, antiU1-RNP, and PM/Scl. Diffuse cutaneous SSc (dcSSc) is characterized by anti-Scl 70 antibody (anti-topoisomerase I antibody, TOPO), anti-RNA polymerase III, and anti-U3RNP [71]. Severe lung disease is the hallmark of anti-TOPOpositive dcSSC patients. DcSSc patients with anti-RNA polymerase III have the most severe skin disease and the highest frequency of renal crisis. Patients with the nucleolar antibody anti-U3-RNP have dcSSc with multiorgan involvement [71].

The autoimmune basis of association between PBC and SSc was first established by the presence of AMA in approximately $5 \%$ of patients with scleroderma and ACA in one-quarter of patients with $\mathrm{PBC}$ [55]. A positive ACA is reported in $9-30 \%$ of $\mathrm{PBC}$ patients [59, 72-75] and in $22-25 \%$ of all SSc patients, almost all of which have lcSSc. Conversely, up to $25 \%$ of SSc patients are AMA positive, but the high prevalence rates of AMA are probably secondary to referral bias and overestimate the frequency of AMA in SSc [76-79]. Another interesting point which needs attention is that of studies reporting a relatively high prevalence of AMA negative $\mathrm{PBC}$ in patients with SSC or other autoimmune diseases $[51,80]$ the autoantibody profile of SSc patients with AMA-negative $\mathrm{PBC}$ may require the use of highly sensitive immunoassays for the detection of AMA. It has been shown that such assays are able to detect AMA in serum samples from SSc patients characterized as AMA negative by indirect immunofluorescence, and this may be the case for other PBC-specific autoantibodies, such as ANA specific for sp100 $[11,12,50]$.
ACA positivity is greater in $\mathrm{PBC}-\mathrm{SSc}$ than in either disease in isolation, but there is no cross-reactivity between mitochondrial and centromere antigens [81]. Because ACA have been detected not only in SSc but also in other autoimmune diseases [82-85] including $\mathrm{PBC}[72,86]$, the clinical significance of ACA in $\mathrm{PBC}$ has been the focus of ongoing research. Three major centromere antigens have been recognized: centromere protein A (CENP-A, $18 \mathrm{kD}$ polypeptide), centromere protein $\mathrm{B}$ (CENP-B, $80 \mathrm{kD}$ polypeptide), and centromere protein C (CENP-C, $140 \mathrm{kD}$ polypeptide). One study attempted to identify the major epitope of ACA in sera obtained from patients with $\mathrm{PBC}$ and to classify the correlation between the presence of ACA epitopes and the clinical features in patients with $\mathrm{PBC}$ [87]. The serological results obtained were compared with clinical features of lcSSc in PBC. Forty-one patients with PBC were studied: 10 out of $16(63 \%)$ patients with ACA (all anti-CENP A) had one or more lcSSc feature. The higher incidence of Raynaud's phenomenon seen in ACA-positive patients with $\mathrm{PBC}$ than that in ACA-negative patients with $\mathrm{PBC}$ suggested a close association of the presence of ACA with clinical features of lcSSc in patients with PBC [87]. From the results of this study, it was proposed that there is a subset of $\mathrm{PBC}$ patients with scleroderma who are ACA positive and differ from both ACA-negative PBC-SSc and ACA-negative $\mathrm{PBC}$ non-SSc patients, based on their clinical features and ACA epitope reactivity [87].

Over the past two years, a tremendous amount of data has come available as to the genetics underlying PBC and SSc. In regards to SSc, several HLA and non-HLA regions have been identified [88], with HLA regions showing variability among ethnic groups. Positive HLA associations in whites and Hispanics include HLADRB1*1104, DQA1*0501, DQB1*0301 [89]. Negative associations in those groups included DRB $1^{*} 0701, \mathrm{DQA} 1^{*} 0201$, DQB1*0202, and DRB1*1501 [89]. Positive HLA associations in African Americans included HLA-DRB1*0804, 
$\mathrm{DQA}^{*} 0501$, and DQB1*0301 [89]. That study also noted that ACA positivity was closely associated with HLA$\mathrm{DQB}^{*} 0501$ [89], and another study found an association between TOPO positivity and HLA-DRB1*1104 [90]. A smaller study of a Spanish cohort showed similar HLA findings to those noted above [90]. Several non-HLA regions have also been identified in SSc. These include STAT4 [88, 91-94], IRF5 [88, 95, 96], BANK1 [97, 98], TNSF4 [99], TBX21 [92], IL-23R [100], and C8orf13-BLK [101] among others [88]. As with SSc, several HLA and nonHLA regions have been identified in PBC. HLA regions include DRB1, DQA1, DQB1, and DQA2 [102, 103]. NonHLA regions include IRF5, STAT4, SPIB, IKZF3-ORMDL3, IL12A, IL12RB, MMEL1, DENND1B, CD80, IL7, CXCR5, TNFRSF1A, CLEC16A, and NKFB1 [104-106]. Interestingly, PBC and SSc have several genes in common: HLA-DRB1, DQA1, DQB1, IRF5, and STAT4, although it should be noted that DR11, which is positively associated with SSc, is considered protective in PBC $[88,105]$.

Infectious agents have been implicated in the pathogenesis of both SSc and PBC. A number of organisms, such as $E$. coli, have been strongly associated with PBC [22, 107, 108], but not with SSc. Helicobacter pylori and Chlamydia have been implicated in both conditions [109-119]; however, some studies indicate the Chlamydia is not involved [72, 120, 121]. It is possible that certain infectious organisms contributes to the development of PBC or SSc in isolation and that other organisms induce the disease in both conditions.

2.3. Screening and Diagnosis of PBC in SSc Patients and Vice Versa. Given the overlap between PBC with SSc and vice versa, including ACA positivity in $\mathrm{PBC}$ patients and AMA positivity in SSc patients, the major challenge remains to clarify which screening method would be best for early diagnosis of the associated conditions.

Firstly, routine screening for PBC-specific antibodies in patients with SSc needs to be further refined. Recently, Norman et al. investigated the presence of antibodies against PBC disease-specific mitochondrial antigens and antibodies against the sp100 nuclear body antigen in 52 patients with SSc, by using two commercially available ELISAs [79]. In that study, $13 \%$ of cases were positive for AMA and $2 \%$ for ANA (anti-sp100), and one patient (2\%) was diagnosed with symptomatic PBC [79]. These figures were reproduced by Mytilinaiou et al., who confirmed $13.5 \%$ positive results with ELISA testing for antibodies against PBC diseasespecific mitochondrial antigens in 37 SSc patients [78]. However, this was not confirmed with the conventional indirect immunofluorescence based on unfixed rodent kidney, liver, stomach tissue sections, or HEp-2 cells as antigenic substrates, and none of the ELISA-positive patients showed features of PBC [78]. It remains to be clarified whether ELISA testing is less specific with false positive results or that it simply represents a more sensitive method with respect to indirect immunofluorescence, which should currently remain the technique of choice.

Nevertheless, the presence of AMA can precede clinical symptoms of PBC. Indeed, Mitchison et al. and Metcalf et al. showed that the vast majority of AMA-positive subjects have typical histological features of PBC despite being asymptomatic with normal biochemistry $[17,122]$. Furthermore, the study by Prince et al. suggested that $36 \%$ of initially asymptomatic PBC patients would become symptomatic within a median time of 5 years [123]. Thus, AMA-positive SSc cases require immediate attention and close, long-term monitoring for early detection of symptoms, signs, and liver biochemistry suggestive of chronic cholestatic liver disease. Routine followup of AMA-positive SSc patients should include liver tests (alanine aminotransferase, aspartate aminotransferase, $\gamma$-glutamyl transpeptidase, alkaline phosphatase, albumin, bilirubin, international normalized ratio), thyroid function, and possibly an annual ultrasound abdominal scan. Transient elastography of the liver has been used to assess biliary fibrosis in patients with PBC [124]. This test is emerging as a useful screening tool to detect undiagnosed chronic liver disease in apparently healthy subjects [125]. Whether patients with SSc, who are tested positive for PBC-specific AMA, need regular checks with transient elastography or more common tests, such as liver ultrasound, needs to be evaluated in large prospective multicentre studies. Currently, there is no evidence that either of these would be of value. Figure 1 illustrates the diagnostic and screening algorithm for PBC in SSc patients.

Screening PBC patients for ACA is not mandatory but can be considered, especially in the presence of diseaserelated symptomatology. Nakamura et al. reported that, in PBC patients, ACA positivity was significantly associated with more severe ductular pathology on liver histology and was a significant risk factor for the development of portal hypertension [126]. In another study, ACA-positive PBC patients without clinical features of SSc were shown to have similar symptoms and signs at diagnosis [49]. Although ACA positivity is not pathognomic of SSc, it is associated with an increased risk of developing connective tissue disease [127]. One review [128] reported a sensitivity of $32 \%(17-56 \%)$ for SSc and 57\% (32-96\%) for lcSSc and specificity of at least 93\%, while ACA positivity was present in $5 \%$ of patients with other connective tissue diseases and less than $1 \%$ of disease-free controls. Since ACA could be predictive of rheumatic disorders, it has been suggested that an assessment of PBC patients should always include screening for SSc-related symptoms, such as Raynaud's phenomenon and CREST-related symptoms (calcinosis, Raynaud's phenomenon, esophageal dysmotility, sclerodactyly, and telangiectasia) [129]. The use of nailfold videocapillaroscopy in patients suspected of having connective tissue disease may be a useful indicator. Some evidence suggests that this assessment can be useful for the diagnostic and/or clinical management of patients with PBC and suspected SSc. Experimental and clinical observation suggests that patients with $\mathrm{PBC}$ have endothelial dysfunction [130]. In an interesting study, nailfold videocapillaroscopy abnormalities were found in $91 \%$ of patients with $\mathrm{PBC}$, and capillary alterations characteristic of SSc were found in 54\% [131]. Eleven out of the 22 PBC patients (50\%) had extrahepatic signs of connective tissue disease with most being related to SSc, while patients with other types of chronic liver disease did not present with rheumatic 


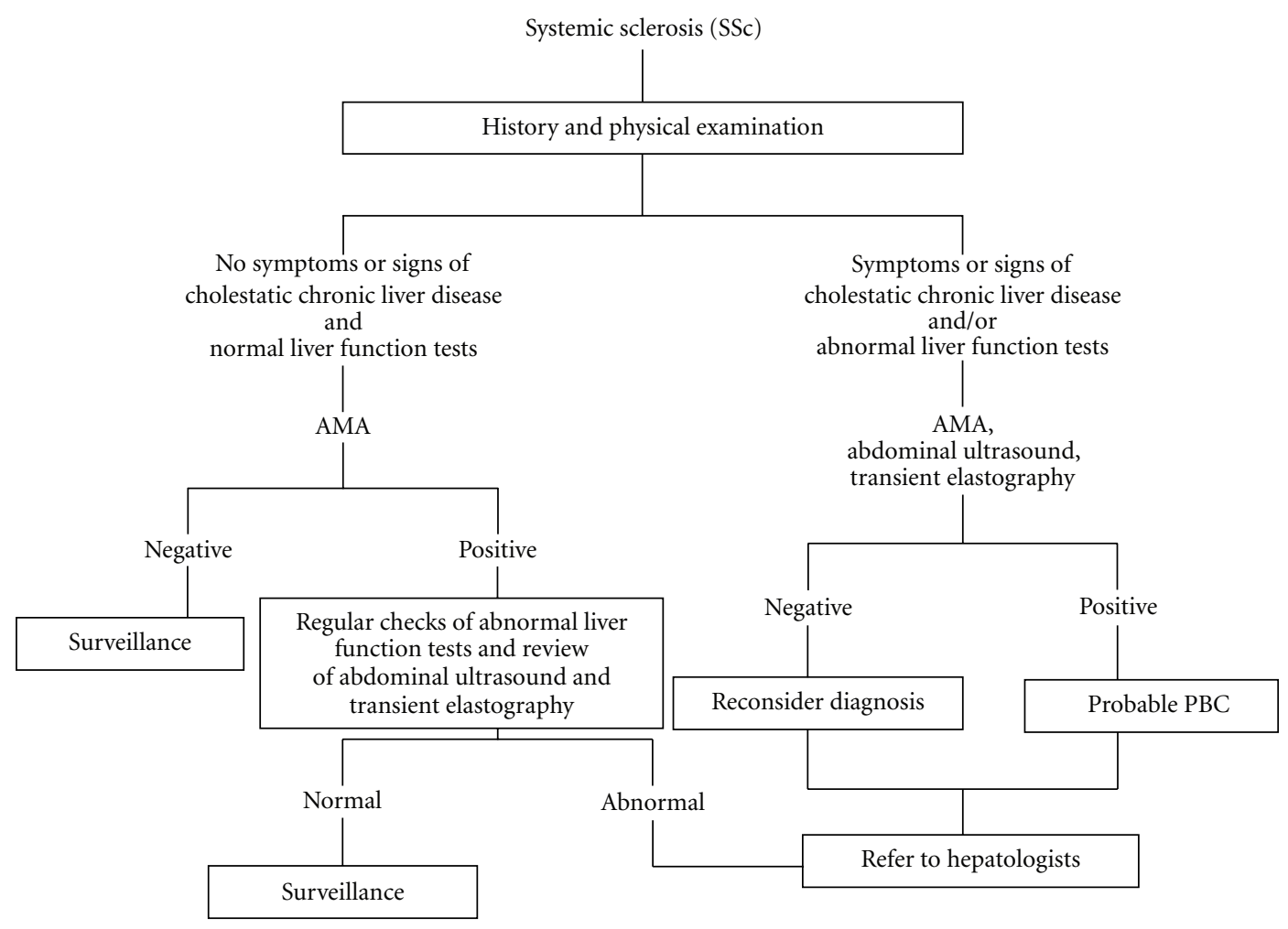

FIGURE 1: A proposed algorithm for the screening and diagnosis of primary biliary cirrhosis (PBC) in patients with established systemic sclerosis (SSc).

manifestations [131]. In PBC patients, there was a significant association between SSc capillary pattern and rheumatic manifestations. The high prevalence of nailfold capillary abnormalities characteristic of SSc in patients with PBC, and correlation with sclerodermal manifestations, suggests that this capillaroscopic finding could be a useful indicator to investigate rheumatic manifestations in these patients [131]. Further clinical assessment of organ involvement (especially lung by spirometry) in association with evaluation of pulmonary artery pressure on echocardiography should be considered in PBC patients with a definite diagnosis of SSc. A proposed diagnostic and screening algorithm for SSc in PBC patients is presented in Figure 2.

2.4. Clinical Presentation and Prognosis. In approximately $60 \%$ of the cases, the clinical presentation of SSc precedes that of PBC. The demographics of the disease in patients with overlapping features are not well defined. For example, it is not clear whether in the PBC-SSc group the diagnosis of $\mathrm{PBC}$ occurs at a lower age than that in patients with $\mathrm{PBC}$ alone. In a study of $43 \mathrm{PBC}$-SSc patients, the median age at diagnosis of PBC made after SSc diagnosis was lower (46.1 years) than in PBC diagnosed before SSc (51.1 years). This was lower than the diagnosis in $\mathrm{PBC}$ alone, with a median age of 53.2 years at diagnosis [49]. The different age at diagnosis in the PBC-SSc patients, compared to patients with $\mathrm{PBC}$ alone, was probably due to the effect of lead time bias (i.e., screening for $\mathrm{PBC}$ in SSc patients and thus early diagnosis of asymptomatic $\mathrm{PBC}$, since $56 \%$ presented with SSc alone).
PBC-SSc patients were reported to have a higher incidence of a first episode of spontaneous bacterial peritonitis and septicaemia during followup with respect to patients with $\mathrm{PBC}$ alone. This is likely due to an increased risk of infection due to immune abnormalities and organ system manifestations associated with SSc [132].

Both SSc and PBC are associated with increased morbidity and mortality compared with the general population $[123,133-139]$. Among the disease-related causes of mortality in SSc patients, pulmonary fibrosis, pulmonary arterial hypertension, and cardiac causes (mainly heart failure and arrhythmias) are reported to account for the majority of deaths. The most frequent non-SSc-related causes of death are infections, malignancies, and cardiovascular causes [140]. In PBC patients, liver-related causes account for roughly $50 \%$ of deaths, whereas cardio- and cerebrovascular causes together with malignancies are responsible for the non-liver-related deaths $[139,141]$. Some case reports [62, 142] suggest that $\mathrm{PBC}$ in association with SSc is associated with a more favourable prognosis than $\mathrm{PBC}$ alone, whereas others reported increased mortality due to SSc [143]. In the study which included $43 \mathrm{PBC}-\mathrm{SSc}$ patients, liver disease had a slower progression in PBC-SSc compared to matched patients with $\mathrm{PBC}$ alone. A lower rate of liver transplantation and liver-related deaths was demonstrated in $\mathrm{PBC}-$ SSc patients compared to patients with $\mathrm{PBC}$ alone, and these differences were not due to earlier SSc-related deaths [49]. However, the improvement in liver-related survival in the PBC-SSc cohort was outweighed by an increase in 


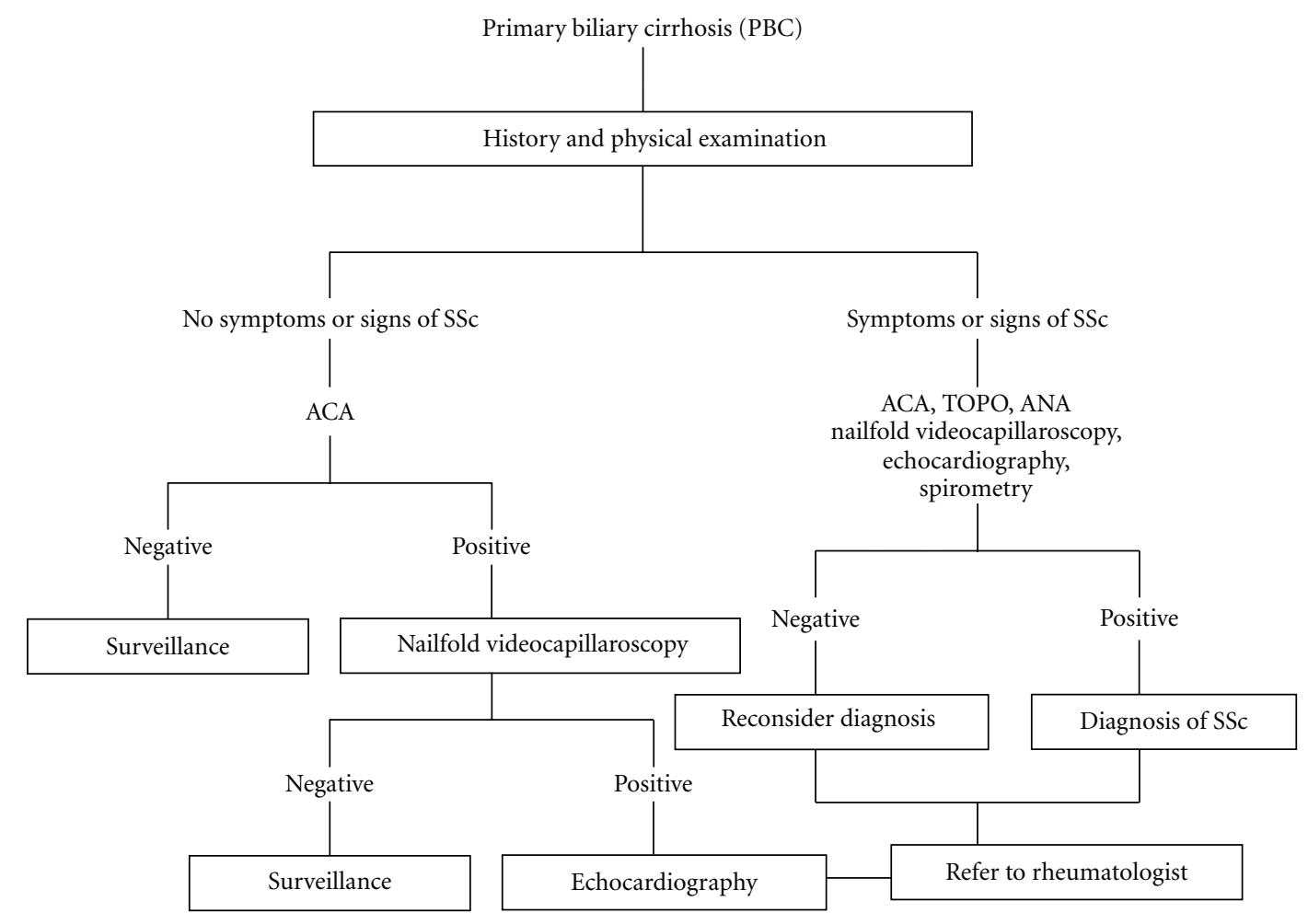

FIGURE 2: A proposed algorithm for the screening and diagnosis of systemic sclerosis (SSc) in patients with established primary biliary cirrhosis (PBC).

non-liver-related deaths due to SSc, and, thus, overall survival was not different in PBC-SSc patients and those with $\mathrm{PBC}$ alone [49]. These data emphasize the importance of comorbidity in PBC. More data on the outcome of patients with $\mathrm{PBC}$ and $\mathrm{PBC}$ with SSc are needed. If patients with $\mathrm{PBC}$ and SSc have a lower rate of liver transplantation and liver-related deaths compared to patients with $\mathrm{PBC}$ alone [49], it would be expected that patients with PBC and SSc-related ACA would also have better prognosis than their seronegative counterparts, but this does not appear to be the case [126]. It may be that the outcome of patients with ACA-positive PBC, who do not have SScrelated symptoms, differs from that of ACA-positive SSc and PBC overlap.

Prince and colleagues observed an increase in nonhepatic deaths in asymptomatic PBC, even with a reduced liver-related mortality, in comparison with symptomatic PBC [123]. Since the causes of death in PBC-SSc patients are mainly due to SSc and not to liver disease, these patients may need different prognostic models in order to better predict their liver-related survival. Prognostic models for PBC alone may not be applicable for PBC associated with $\mathrm{SSc}$ or for other associated autoimmune diseases to assess the risk of liver-related mortality and the need for liver transplantation.

2.5. Therapy. All PBC patients with abnormal liver biochemistry should be considered for specific therapy. UDCA at the dose of $13-15 \mathrm{mg} / \mathrm{kg} /$ day on a long-term basis is currently considered the mainstay of therapy for PBC [18]. In the early stages of $\mathrm{PBC}$, UDCA protects injured cholangiocytes against the toxic effects of bile acids. In later stages of the disease, UDCA stimulates impaired hepatocellular secretion, mainly by posttranscriptional mechanisms [144]. In addition, stimulation of ductular alkaline choleresis and inhibition of bile acid-induced hepatocyte and cholangiocyte apoptosis are included among the beneficial effects of UDCA in PBC [144]. UDCA has been demonstrated to markedly decrease serum bilirubin, alkaline phosphatase, $\gamma$-glutamyl transpeptidase, cholesterol, and immunoglobulin M levels and to ameliorate histological features in patients with $\mathrm{PBC}$ in comparison to placebo treatment [145-149]. However, no significant effects on fatigue or pruritus were observed in these large trials nor were effects on survival [150]. Favorable longterm effects of UDCA are observed in patients with early disease and in those with a good biochemical response, which should be assessed after one year from start of treatment [18]. A good biochemical response after one year of UDCA treatment is currently defined by a serum bilirubin $\leq 1 \mathrm{mg} / \mathrm{dL}$ $(17 \mu \mathrm{mol} / \mathrm{L})$, alkaline phosphatase $\leq 3 \mathrm{x}$ ULN, and aspartate aminotransferase $\leq 3 \mathrm{x}$ ULN, according to the "Paris criteria" [151]. The "Barcelona criteria" indicates a good response with a $40 \%$ decrease or normalization of serum alkaline phosphatase [152].

Whether treatment with UDCA has an effect on the symptoms and the outcome of SSc remains poorly understood. Prospective studies of patients with PBC-associated SSc who are followed-up for many years under UDCA treatment are needed to address this issue. 
The treatment of SSc is complex and may include drugs with hepatotoxic potential. For example, the use of endothelin-1 receptor antagonist bosentan, which is the treatment of choice for SSc-related pulmonary artery hypertension, has been associated with increased risk of elevated aminotransferases [153-155]. When PBC is present, the management of SSc patients is more challenging, as this autoimmune liver disease may pose further risk factors or unwanted complications. Whichever therapy is to be implemented, it is recommended that collaboration takes place between specialists responsible for the care of these patients.

\section{Conclusions}

The association of SSc and $\mathrm{PBC}$ is a rare but intriguing autoimmune syndrome which challenges the expertise and interests of hepatologists and rheumatologists in terms of early diagnosis and shared management. A major effort should be made for continuing collaborative research in this field aimed at achieving a better understanding of the immunopathogenesis, genetic background, and demographic features of patients at higher risk of developing the associated conditions. These findings may also contribute to the development of specific protocols for preventing development and evolution of the two associated diseases.

\section{Abbreviations}

ACA: Anticentromere antibody

AMA: Antimitochondrial antibody

ANA: Antinucluear antibody

CENP-A: Centromere protein A

CENP-B: Centromere protein $\mathrm{B}$

CENP-C: Centromere protein C

dcSSc: Diffuse cutaneous systemic sclerosis

ELISA: Enzyme-linked immunosorbent assay

lcSSc: Limited cutaneous systemic sclerosis

PBC: $\quad$ Primary biliary cirrhosis

SSc: $\quad$ Systemic sclerosis

Anti-TOPO: Anti-topoisomerase (anti-Scl-70) antibody

UDCA: Ursodeoxycholic acid

ULN: $\quad$ Upper limit of normal.

\section{Authors' Contribution}

D. P. Bogdanos and A. K. Burroughs are equally contributed to the paper.

\section{Conflict of Interest}

None of the authors has a conflict of interest to declare.

\section{References}

[1] M. M. Kaplan and M. E. Gershwin, "Primary biliary cirrhosis," The New England Journal of Medicine, vol. 353, no. 12, pp. 1261-1273, 2005.

[2] S. Hohenester, R. P. J. Oude-Elferink, and U. Beuers, "Primary biliary cirrhosis," Seminars in Immunopathology, vol. 31, no. 3, pp. 283-307, 2009.
[3] J. Neuberger, "Primary biliary cirrhosis," The Lancet, vol. 350, no. 9081, pp. 875-879, 1997.

[4] H. Rautiainen, V. Salomaa, S. Niemelä et al., "Prevalence and incidence of primary biliary cirrhosis are increasing in Finland," Scandinavian Journal of Gastroenterology, vol. 42, no. 11, pp. 1347-1353, 2007.

[5] O. E. W. James, R. Bhopal, D. Howel, J. Gray, A. D. Burt, and J. V. Metcalf, "Primary biliary cirrhosis once rare, now common in the United Kingdom?" Hepatology, vol. 30, no. 2, pp. 390-394, 1999.

[6] W. R. Kim, K. D. Lindor, G. R. Locke et al., "Epidemiology and natural history of primary biliary cirrhosis in a U.S. community," Gastroenterology, vol. 119, no. 6, pp. 16311636, 2000.

[7] S. Sood, P. J. Gow, J. M. Christie, and P. W. Angus, "Epidemiology of primary biliary cirrhosis in Victoria, Australia: high prevalence in migrant populations," Gastroenterology, vol. 127, no. 2, pp. 470-475, 2004.

[8] D. P. Bogdanos, H. Baum, and D. Vergani, "Antimitochondrial and other autoantibodies," Clinics in Liver Disease, vol. 7, no. 4, pp. 759-777, 2003.

[9] W. Bernal, F. Meda, Y. Ma, D. P. Bogdanos, and D. Vergani, "Disease-specific autoantibodies in patients with acute liver failure: the King's College London experience," Hepatology, vol. 47, no. 3, pp. 1096-1097, 2008.

[10] D. P. Bogdanos and L. Komorowski, "Disease-specific autoantibodies in primary biliary cirrhosis," Clinica Chimica Acta, vol. 412, no. 7-8, pp. 502-512, 2011.

[11] C. Dähnrich, A. Pares, L. Caballeria et al., "New ELISA for detecting primary biliary cirrhosis-specific antimitochondrial antibodies," Clinical Chemistry, vol. 55, no. 5, pp. 978985, 2009.

[12] H. Liu, G. L. Norman, Z. Shums et al., "PBC Screen: an IgG/IgA dual isotype ELISA detecting multiple mitochondrial and nuclear autoantibodies specific for primary biliary cirrhosis," Journal of Autoimmunity, vol. 35, no. 4, pp. 436442, 2010.

[13] Y. Ma, M. G. Thomas, M. Okamoto et al., "Key residues of a major cytochrome P4502D6 epitope are located on the surface of the molecule," Journal of Immunology, vol. 169, no. 1, pp. 277-285, 2002.

[14] E. I. Rigopoulou, E. T. Davies, D. P. Bogdanos et al., "Antimitochondrial antibodies of immunoglobulin G3 subclass are associated with a more severe disease course in primary biliary cirrhosis," Liver International, vol. 27, no. 9, pp. 12261231, 2007.

[15] D. Vergani and D. P. Bogdanos, "Positive markers in AMAnegative PBC," American Journal of Gastroenterology, vol. 98, no. 2, pp. 241-243, 2003.

[16] L. Wen, Y. Ma, D. P. Bogdanos et al., "Pédiatrie autoimmune liver diseases: the molecular basis of humoral and cellular immunity," Current Molecular Medicine, vol. 1, no. 3, pp. 379-389, 2001.

[17] J. V. Metcalf, H. C. Mitchison, J. M. Palmer, D. E. Jones, M. F. Bassendine, and O. F. W. James, "Natural history of early primary biliary cirrhosis," The Lancet, vol. 348, no. 9039, pp. 1399-1402, 1996.

[18] European Association for the Study of the Liver, "EASL Clinical Practice Guidelines: management of cholestatic liver diseases," Journal of Hepatology, vol. 51, no. 2, pp. 237-267, 2009. 
[19] S. Oertelt, R. Rieger, C. Selmi et al., "A sensitive bead assay for antimitochondrial antibodies: chipping away at AMAnegative primary biliary cirrhosis," Hepatology, vol. 45, no. 3, pp. 659-665, 2007.

[20] J. C. Courvalin and H. J. Worman, "Nuclear envelope protein autoantibodies in primary biliary cirrhosis," Seminars in Liver Disease, vol. 17, no. 1, pp. 79-90, 1997.

[21] P. Invernizzi, C. Selmi, C. Ranftler, M. Podda, and J. Wesierska-Gadek, "Antinuclear antibodies in primary biliary cirrhosis," Seminars in Liver Disease, vol. 25, no. 3, pp. 298310, 2005.

[22] D. P. Bogdanos, H. Baum, D. Vergani, and A. K. Burroughs, "The role of E. coli infection in the pathogenesis of primary biliary cirrhosis," Disease Markers, vol. 29, no. 6, pp. 301-311, 2010.

[23] D. P. Bogdanos and D. Vergani, "Origin of cross-reactive autoimmunity in primary biliary cirrhosis," Liver International, vol. 26, no. 6, pp. 633-635, 2006.

[24] D. P. Bogdanos and D. Vergani, "Bacteria and primary biliary cirrhosis," Clinical Reviews in Allergy and Immunology, vol. 36, no. 1, pp. 30-39, 2009.

[25] M. E. Gershwin and I. R. Mackay, "Primary biliary cirrhosis: paradigm or paradox for autoimmunity," Gastroenterology, vol. 100, no. 3, pp. 822-833, 1991.

[26] M. E. Gershwin and I. R. Mackay, "The causes of primary biliary cirrhosis: convenient and inconvenient truths," Нераtology, vol. 47, no. 2, pp. 737-745, 2008.

[27] D. E. J. Jones, "Enesis of primary biliary cirrhosis," Gut, vol. 56, no. 11, pp. 1615-1624, 2007.

[28] I. R. Mackay, S. Whittingham, S. Fida et al., "The peculiar autoimmunity of primary biliary cirrhosis," Immunological Reviews, vol. 174, pp. 226-237, 2000.

[29] S. Shimoda, M. Nakamura, H. Ishibashi, K. Hayashida, and Y. Niho, "HLA DRB4 0101-restricted immunodominant T cell autoepitope of pyruvate dehydrogenase complex in primary biliary cirrhosis: evidence of molecular mimicry in human autoimmune diseases," Journal of Experimental Medicine, vol. 181, no. 5, pp. 1835-1845, 1995.

[30] S. Shimoda, M. Nakamura, H. Shigematsu et al., "Mimicry peptides of human PDC-E2 163-176 peptide, the immunodominant T- cell epitope of primary biliary cirrhosis," Hepatology, vol. 31, no. 6, pp. 1212-1216, 2000.

[31] S. Shimoda, J. Van De Water, A. Ansari et al., "Identification and precursor frequency analysis of a common T cell epitope motif in mitochondrial autoantigens in primary biliary cirrhosis," Journal of Clinical Investigation, vol. 102, no. 10, pp. 1831-1840, 1998.

[32] D. Smyk et al., "Autoimmunity and environment: am I at risk?," Clinical Reviews in Allergy and Immunology. In press.

[33] D. Smyk, M. G. Mytilinaiou, E. I. Rigopoulou, and D. P. Bogdanos, "PBC triggers in water reservoirs, coal mining areas and waste disposal sites: from Newcastle to New York," Disease Markers, vol. 29, no. 6, pp. 337-344, 2010.

[34] D. P. Bogdanos, H. Baum, F. Gunsar et al., "Extensive homology between the major immunodominant mitochondrial antigen in primary biliary cirrhosis and Helicobacter pylori does not lead to immunological cross-reactivity," Scandinavian Journal of Gastroenterology, vol. 39, no. 10, pp. 981-987, 2004.

[35] D. P. Bogdanos, A. Pares, H. Baum et al., "Disease-specific cross-reactivity between mimicking peptides of heat shock protein of mycobacterium gordonae and dominant epitope of E2 subunit of pyruvate dehydrogenase is common in Spanish but not British patients with primary biliary cirrhosis," Journal of Autoimmunity, vol. 22, no. 4, pp. 353-362, 2004.

[36] L. Muratori, D. P. Bogdanos, P. Muratori et al., "Susceptibility to thyroid disorders in hepatitis C," Clinical Gastroenterology and Hepatology, vol. 3, no. 6, pp. 595-603, 2005.

[37] D. Polymeros, D. P. Bogdanos, R. Day, D. Arioli, D. Vergani, and A. Forbes, "Does cross-reactivity between mycobacterium avium paratuberculosis and human intestinal antigens characterize Crohn's disease?" Gastroenterology, vol. 131, no. 1, pp. 85-96, 2006.

[38] D. Vergani, D. P. Bogdanos, and H. Baum, "Unusual suspects in primary biliary cirrhosis," Hepatology, vol. 39, no. 1, pp. 38-41, 2004.

[39] M. E. Gershwin, C. Selmi, H. J. Worman et al., "Risk factors and comorbidities in primary biliary cirrhosis: a controlled interview-based study of 1032 patients," Hepatology, vol. 42, no. 5, pp. 1194-1202, 2005.

[40] M. Hudson, A. Rojas-Villarraga, P. Coral-Alvarado et al., "Polyautoimmunity and familial autoimmunity in systemic sclerosis," Journal of Autoimmunity, vol. 31, no. 2, pp. 156159, 2008.

[41] R. Poupon, "Primary biliary cirrhosis: a 2010 update," Journal of Hepatology, vol. 52, no. 5, pp. 745-758, 2010.

[42] S. Abraham, S. Begum, and D. Isenberg, "Hepatic manifestations of autoimmune rheumatic diseases," Annals of the Rheumatic Diseases, vol. 63, no. 2, pp. 123-129, 2004.

[43] L. G. Bartholomew, J. C. Cain, R. K. Winkelmann, and A. H. Baggenstoss, "Chronic disease of the liver associated with systemic scleroderma," The American Journal of Digestive Diseases, vol. 9, no. 1, pp. 43-55, 1964.

[44] I. M. Murray-Lyon, R. P. Thompson, I. D. Ansell, and R. Williams, "Scleroderma and primary biliary cirrhosis," British Medical Journal, vol. 1, no. 717, pp. 258-259, 1970.

[45] W. A. D’Angelo, J. F. Fries, A. T. Masi, and L. E. Shulman, "Pathologic observations in systemic sclerosis (scleroderma). A study of fifty-eight autopsy cases and fifty-eight matched controls," The American Journal of Medicine, vol. 46, no. 3, pp. 428-440, 1969.

[46] D. L. Tuffanelli and R. K. Winkelmann, "Systemic scleroderma, a clinical study of 727 cases," Archives of Dermatology, vol. 84, pp. 359-371, 1961.

[47] T. B. Reynolds, E. K. Denison, H. D. Frankl, F. L. Lieberman, and R. L. Peters, "Primary biliary cirrhosis with scleroderma, Raynaud's phenomenon and telangiectasia. New syndrome," The American Journal of Medicine, vol. 50, no. 3, pp. 302-312, 1971.

[48] S. T. O’Brien, W. M. Eddy, and E. L. Krawitt, "Primary biliary cirrhosis associated with scleroderma," Gastroenterology, vol. 62, no. 1, pp. 118-121, 1972.

[49] C. Rigamonti, L. M. Shand, M. Feudjo et al., "Clinical features and prognosis of primary biliary cirrhosis associated with systemic sclerosis," Gut, vol. 55, no. 3, pp. 388-394, 2006.

[50] S. Assassi, M. J. Fritzler, F. C. Arnett et al., "Primary biliary cirrhosis (PBC), $\mathrm{PBC}$ autoantibodies, and hepatic parameter abnormalities in a large population of systemic sclerosis patients," Journal of Rheumatology, vol. 36, no. 10, pp. 22502256, 2009.

[51] F. E. Watt, O. F. W. James, and D. E. J. Jones, "Patterns of autoimmunity in primary biliary cirrhosis patients and their families: a population-based cohort study," Quarterly Journal of Medicine, vol. 97, no. 7, pp. 397-406, 2004. 
[52] S. Akimoto, O. Ishikawa, Y. Muro, H. Takagi, T. Tamura, and Y. Miyachi, "Clinical and immunological characterization of patients with systemic sclerosis overlapping primary biliary cirrhosis: a comparison with patients with systemic sclerosis alone," Journal of Dermatology, vol. 26, no. 1, pp. 18-22, 1999.

[53] S. Akimoto, O. Ishikawa, H. Takagi, and Y. Miyachi, "Immunological features of patients with primary biliary cirrhosis (PBC) overlapping systemic sclerosis: a comparison with patients with PBC alone," Journal of Gastroenterology and Hepatology, vol. 13, no. 9, pp. 897-901, 1998.

[54] B. Brzezińska-Kolarz, A. Undas, A. Dyczek, and J. Musiał, "Reynolds syndrome: the combination of scleroderma and primary biliary cirrhosis. Case report," Polskie Archiwum Medycyny Wewnetrznej, vol. 105, no. 3, pp. 231-234, 2001.

[55] A. K. Clarke, R. M. Galbraith, E. B. D. Hamilton, and R. Williams, "Rheumatic disorders in primary biliary cirrhosis," Annals of the Rheumatic Diseases, vol. 37, no. 1, pp. 42-47, 1978.

[56] Y. Geffroy, R. Colin, and J. Hemet, "Primary biliary cirrhosis and scleroderma," Medecine et Chirurgie Digestives, vol. 2, no. 5, pp. 281-286, 1973.

[57] H. D. Goring et al., "[Coincidence of scleroderma and primary biliary cirrhosis. Results of a systematic study of a dermatologic patient sample]," Der Hautarzt, vol. 49, pp. 361-366, 1998.

[58] S. Maekawa, E. Yano, and S. Shintani, "A case of rheumatoid arthritis associated with progressive systemic sclerosis and primary biliary cirrhosis in the presence of various autoantibodies," Ryumachi, vol. 32, no. 5, pp. 515-521, 1992.

[59] B. Marasini, M. Gagetta, V. Rossi, and P. Ferrari, "Rheumatic disorders and primary biliary cirrhosis: an appraisal of 170 Italian patients," Annals of the Rheumatic Diseases, vol. 60, no. 11, pp. 1046-1049, 2001

[60] F. C. Powell, A. L. Schroeter, and E. R. Dickson, "Primary biliary cirrhosis and the CREST syndrome: a report of 22 cases," Quarterly Journal of Medicine, vol. 62, no. 237, pp. 7582, 1987.

[61] S. Sherlock and P. J. Scheuer, "The presentation and diagnosis of 100 patients with primary biliary cirrhosis," The New England Journal of Medicine, vol. 289, no. 13, pp. 674-678, 1973.

[62] V. Stadie, J. Wohlrab, and W. C. Marsch, “The Reynolds' syndrome- a rare combination of two autoimmune diseases," Medizinische Klinik, vol. 97, no. 1, pp. 40-43, 2002.

[63] Y. Ueno, M. Shibata, and Y. Onozuka, "Association of extrahepatic autoimmune diseases in primary biliary cirrhosisclinical statistics and analyses of Japanese and non-Japanese cases," Nippon Rinsho, vol. 56, no. 10, pp. 2687-2698, 1998.

[64] K. S. Culp, C. R. Fleming, and J. Duffy, "Autoimmune associations in primary biliary cirrhosis," Mayo Clinic Proceedings, vol. 57, no. 6, pp. 365-370, 1982.

[65] V. Modena, C. Marengo, and A. Amoroso, "Primary biliary cirrhosis and rheumatic diseases: a clinical, immunological and immunogenetical study," Clinical and Experimental Rheumatology, vol. 4, no. 2, pp. 129-134, 1986.

[66] C. Corpechot, Y. Chrétien, O. Chazouillères, and R. Poupon, "Demographic, lifestyle, medical and familial factors associated with primary biliary cirrhosis," Journal of Hepatology, vol. 53, no. 1, pp. 162-169, 2010.

[67] A. Parikh-Patel, E. B. Gold, H. Worman, K. E. Krivy, and M. E. Gershwin, "Risk factors for primary biliary cirrhosis in a cohort of patients from the United States," Hepatology, vol. 33, no. 1, pp. 16-21, 2001.
[68] C. Feghali-Bostwick, T. A. Medsger, and T. M. Wright, "Analysis of systemic sclerosis in twins reveals low concordance for disease and high concordance for the presence of antinuclear antibodies," Arthritis and Rheumatism, vol. 48, no. 7, pp. 1956-1963, 2003.

[69] C. Selmi, M. J. Mayo, N. Bach et al., "Primary biliary cirrhosis in monozygotic and dizygotic twins: genetics, epigenetics, and environment," Gastroenterology, vol. 127, no. 2, pp. 485492, 2004.

[70] M. J. Mayo, R. N. Jenkins, B. Combes, and P. E. Lipsky, "Association of clonally expanded T cells with the syndrome of primary biliary cirrhosis and limited scleroderma," Нераtology, vol. 29, no. 6, pp. 1635-1642, 1999.

[71] V. D. Steen, "Autoantibodies in systemic sclerosis," Seminars in Arthritis and Rheumatism, vol. 35, no. 1, pp. 35-42, 2005.

[72] R. M. Bernstein, M. E. Callender, and J. M. Neuberger, "Anticentromere antibody in primary biliary cirrhosis," Annals of the Rheumatic Diseases, vol. 41, no. 6, pp. 612-614, 1982.

[73] H. L. Chan, Y. S. Lee, H. S. Hong, and T. T. Kuo, "Anticentromere antibodies (ACA): clinical distribution and disease specificity," Clinical and Experimental Dermatology, vol. 19, no. 4, pp. 298-302, 1994.

[74] B. U. Hansen, S. Eriksson, and S. Lindgren, "High prevalence of autoimmune liver disease in patients with multiple nuclear dot, anti-centromere, and mitotic spindle antibodies," Scandinavian Journal of Gastroenterology, vol. 26, no. 7, pp. 707713, 1991.

[75] F. C. Powell, R. K. Winkelmann, and F. Venencie-Lemarchand, "The anticentromere antibody: disease specificity and clinical significance," Mayo Clinic Proceedings, vol. 59, no. 10, pp. 700-706, 1984.

[76] M. J. Chou, M. Y. Lai, S. L. Lee, and G. J. Tsay, "Reactivity of anti-mitochondrial antibodies in primary biliary cirrhosis and systemic sclerosis," Journal of the Formosan Medical Association, vol. 91, no. 11, pp. 1075-1080, 1992.

[77] R. C. Gupta, J. R. Seibold, M. R. Krishnan, and J. C. Steigerwald, "Precipitating autoantibodies to mitochondrial proteins in progressive systemic sclerosis," Clinical and Experimental Immunology, vol. 58, no. 1, pp. 68-76, 1984.

[78] M. G. Mytilinaiou and D. P. Bogdanos, "Primary biliary cirrhosis-specific autoantibodies in patients with systemic sclerosis," Digestive and Liver Disease, vol. 41, no. 12, p. 916, 2009.

[79] G. L. Norman, A. Bialek, S. Encabo et al., "Is prevalence of PBC underestimated in patients with systemic sclerosis?" Digestive and Liver Disease, vol. 41, no. 10, pp. 762-764, 2009.

[80] F. Sakauchi, M. Mori, M. Zeniya, and G. Toda, "Antimitochondrial antibody negative primary biliary cirrhosis in Japan: utilization of clinical data when patients applied to receive public financial aid," Journal of Epidemiology, vol. 16, no. 1, pp. 30-34, 2005.

[81] J. Whyte, D. Hough, P. J. Maddison, and N. J. McHugh, "The association of primary biliary cirrhosis and systemic sclerosis is not accounted for by cross reactivity between mitochondrial and centromere antigens," Journal of Autoimmunity, vol. 7, no. 3, pp. 413-424, 1994.

[82] C. G. M. Kallenberg, G. W. Pastoor, A. A. Wouda, and T. H. The, "Antinuclear antibodies in patients with Raynaud's phenomenon: clinical significance of anticentromere antibodies," Annals of the Rheumatic Diseases, vol. 41, no. 4, pp. 382-387, 1982.

[83] G. A. McCarty, J. R. Rice, M. L. Bembe, and F. A. Barada, "Anticentromere antibody. Clinical correlations and association with favorable prognosis in patients with scleroderma 
variants," Arthritis and Rheumatism, vol. 26, no. 1, pp. 1-7, 1983.

[84] S. Miyawaki, H. Asanuma, S. Nishiyama, and Y. Yoshinaga, "Clinical and serological heterogeneity in patients with anticentromere antibodies," Journal of Rheumatology, vol. 32, no. 8, pp. 1488-1494, 2005.

[85] J. R. Seibold and M. C. Trontell, "Anticentromere antibody and primary pulmonary hypertension," Journal of Rheumatology, vol. 9, no. 4, pp. 607-609, 1982.

[86] D. Makinen, M. Fritzler, P. Davis, and S. Sherlock, "Anticentromere antibodies in primary biliary cirrhosis," Arthritis and Rheumatism, vol. 26, no. 7, pp. 914-917, 1983.

[87] I. Shoji, T. Takagi, and R. Kasukawa, "Anti-centromere antibody and CREST syndrome in patients with primary biliary cirrhosis," Internal Medicine, vol. 31, no. 12, pp. 13481355, 1992.

[88] S. K. Agarwal and J. D. Reveille, "The genetics of scleroderma (systemic sclerosis)," Current Opinion in Rheumatology, vol. 22, no. 2, pp. 133-138, 2010.

[89] F. C. Arnett, P. Gourh, S. Shete et al., "Major histocompatibility complex (MHC) class II alleles, haplotypes and epitopes which confer susceptibility or protection in systemic sclerosis: analyses in 1300 Caucasian, African-American and Hispanic cases and 1000 controls," Annals of the Rheumatic Diseases, vol. 69, no. 5, pp. 822-827, 2010.

[90] C. P. Simeón, V. Fonollosa, C. Tolosa et al., "Association of HLA class II genes with systemic sclerosis in Spanish patients," Journal of Rheumatology, vol. 36, no. 12, pp. 27332736, 2009.

[91] P. Dieudé, M. Guedj, J. Wipff et al., "STAT4 is a genetic risk factor for systemic sclerosis having additive effects with IRF5 on disease susceptibility and related pulmonary fibrosis," Arthritis and Rheumatism, vol. 60, no. 8, pp. 2472-2479, 2009.

[92] P. Gourh, S. K. Agarwal, D. Divecha et al., "Polymorphisms in TBX21 and STAT4 increase the risk of systemic sclerosis: evidence of possible gene-gene interaction and alterations in Th1/Th2 cytokines," Arthritis and Rheumatism, vol. 60, no. 12, pp. 3794-3806, 2009.

[93] B. Rueda, J. Broen, C. Simeon et al., "The STAT4 gene influences the genetic predisposition to systemic sclerosis phenotype," Human Molecular Genetics, vol. 18, no. 11, pp. 20712077, 2009.

[94] N. Tsuchiya, A. Kawasaki, M. Hasegawa et al., "Association of STAT4 polymorphism with systemic sclerosis in a Japanese population," Annals of the Rheumatic Diseases, vol. 68, no. 8, pp. 1375-1376, 2009.

[95] P. Dieudé, M. Guedj, J. Wipff et al., "Association between the IRF5 rs2004640 functional polymorphism and systemic sclerosis: a new perspective for pulmonary fibrosis," Arthritis and Rheumatism, vol. 60, no. 1, pp. 225-233, 2009.

[96] I. Ito, Y. Kawaguchi, A. Kawasaki et al., "Association of a functional polymorphism in the IRF5 region with systemic sclerosis in a Japanese population," Arthritis and Rheumatism, vol. 60, no. 6, pp. 1845-1850, 2009.

[97] P. Dieudé, J. Wipff, M. Guedj et al., "BANK1 is a genetic risk factor for diffuse cutaneous systemic sclerosis and has additive effects with IRF5 and STAT4," Arthritis and Rheumatism, vol. 60, no. 11, pp. 3447-3454, 2009.

[98] B. Rueda, P. Gourh, J. Broen et al., "BANK1 functional variants are associated with susceptibility to diffuse systemic sclerosis in Caucasians," Annals of the Rheumatic Diseases, vol. 69, no. 4, pp. 700-705, 2010.
[99] P. Gourh, F. C. Arnett, F. K. Tan et al., “Association of TNFSF4 (OX40L) polymorphisms with susceptibility to systemic sclerosis," Annals of the Rheumatic Diseases, vol. 69, no. 3, pp. 550-555, 2010.

[100] S. K. Agarwal, P. Gourh, S. Shete et al., "Association of interleukin 23 receptor polymorphisms with anti-topoisomeraseI positivity and pulmonary hypertension in systemic sclerosis," Journal of Rheumatology, vol. 36, no. 12, pp. 2715-2723, 2009.

[101] P. Gourh, S. K. Agarwal, E. Martin et al., "Association of the C8orf13-BLK region with systemic sclerosis in NorthAmerican and European populations," Journal of Autoimmunity, vol. 34, no. 2, pp. 155-162, 2010.

[102] G. M. Hirschfield, X. Liu, C. Xu et al., "Primary biliary cirrhosis associated with HLA, IL12A, and IL12RB2 variants," The New England Journal of Medicine, vol. 360, no. 24, pp. 2544-2555, 2009.

[103] P. T. Donaldson, A. Baragiotta, M. A. Heneghan et al., "HLA class II alleles, genotypes, haplotypes, and amino acids in primary biliary cirrhosis: a large-scale study," Hepatology, vol. 44, no. 3, pp. 667-674, 2006.

[104] G. M. Hirschfield, X. Liu, Y. Han et al., "Variants at IRF5TNPO3, 17q12-21 and MMEL1 are associated with primary biliary cirrhosis," Nature Genetics, vol. 42, no. 8, pp. 655-657, 2010.

[105] X. Liu, P. Invernizzi, Y. Lu et al., "Genome-wide metaanalyses identify three loci associated with primary biliary cirrhosis," Nature Genetics, vol. 42, no. 8, pp. 658-660, 2010.

[106] G. F. Mells, J. A. Floyd, K. I. Morley et al., "Genome-wide association study identifies 12 new susceptibility loci for primary biliary cirrhosis," Nature Genetics, vol. 43, no. 4, pp. 329-332, 2011.

[107] A. K. Burroughs, I. J. Rosenstein, and O. Epstein, "Bacteriuria and primary biliary cirrhosis," Gut, vol. 25, no. 2, pp. 133137, 1984.

[108] S. P. M. Fussey, S. T. Ali, J. R. Guest, O. F. W. James, M. F. Bassendine, and S. J. Yeaman, "Reactivity of primary biliary cirrhosis sera Escherichia coli dihydrolipoamide acetyltransferase (E2p): characterization of the main immunogenic region," Proceedings of the National Academy of Sciences of the United States of America, vol. 87, no. 10, pp. 3987-3991, 1990.

[109] C. Grossman, Z. Dovrish, Y. Shoenfeld, and H. Amital, "Do infections facilitate the emergence of systemic sclerosis?" Autoimmunity Reviews, 2010.

[110] A. Gabrielli, E. V. Avvedimento, and T. Krieg, "Mechanisms of disease: scleroderma," The New England Journal of Medicine, vol. 360, no. 19, pp. 1989-2003, 2009.

[111] G. Macchia, A. Massone, D. Burroni, A. Covacci, S. Censini, and R. Rappuoli, "The Hsp60 protein of Helicobacter pylori: structure and immune response in patients with gastroduodenal diseases," Molecular Microbiology, vol. 9, no. 3, pp. 645652, 1993.

[112] S. B. Randone, S. Guiducci, and M. M. Cerinic, "Systemic sclerosis and infections," Autoimmunity Reviews, vol. 8, no. 1, pp. 36-40, 2008.

[113] A. S. Abdulkarim, L. M. Petrovic, W. R. Kim, P. Angulo, R. V. Lloyd, and K. D. Lindor, "Primary biliary cirrhosis: an infectious disease caused by Chlamydia pneumoniae?" Journal of Hepatology, vol. 40, no. 3, pp. 380-384, 2004.

[114] H. Y. Liu, A. M. Deng, J. Zhang et al., "Correlation of Chlamydia pneumoniae infection with primary biliary cirrhosis," World Journal of Gastroenterology, vol. 11, no. 26, pp. 4108-4110, 2005. 
[115] D. P. Bogdanos, A. Pares, J. Rodés et al., "Primary biliary cirrhosis specific antinuclear antibodies in patients from Spain," American Journal of Gastroenterology, vol. 99, no. 4, pp. 763-765, 2004.

[116] H. O. Nilsson, M. Castedal, R. Olsson, and T. Wadström, "Detection of Helicobacter in the liver of patients with chronic cholestatic liver diseases," Journal of Physiology and Pharmacology, vol. 50, no. 5, pp. 875-882, 1999.

[117] H. O. Nilsson, J. Taneera, M. Castedal, E. Glatz, R. Olsson, and T. Wadström, "Identification of Helicobacter pylori and other Helicobacter species by PCR, hybridization, and partial DNA sequencing in human liver samples from patients with primary sclerosing cholangitis or primary biliary cirrhosis," Journal of Clinical Microbiology, vol. 38, no. 3, pp. 1072-1076, 2000.

[118] I. Nilsson, I. Kornilovs'ka, S. Lindgren, A. Ljungh, and T. Wadström, "Increased prevalence of seropositivity for nongastric Helicobacter species in patients with autoimmune liver disease," Journal of Medical Microbiology, vol. 52, no. 11, pp. 949-953, 2003.

[119] I. Nilsson, S. Lindgren, S. Eriksson, and T. Wadström, "Serum antibodies to Helicobacter hepaticus and Helicobacter pylori in patients with chronic liver disease," Gut, vol. 46, no. 3, pp. 410-414, 2000.

[120] P. S. C. Leung, O. Park, S. Matsumura, A. A. Ansari, R. L. Coppel, and M. E. Gershwin, "Is there a relation between chlamydia infection and primary biliary cirrhosis?" Clinical and Developmental Immunology, vol. 10, no. 2-4, pp. 227233, 2003.

[121] D. Taylor-Robinson, A. W. Sharif, N. S. Dhanjal, and S. D. Taylor-Robinson, "Chlamydia pneumoniae infection is an unlikely cause of primary biliary cirrhosis," Journal of Hepatology, vol. 42, no. 5, pp. 779-780, 2005.

[122] H. C. Mitchison, M. F. Bassendine, and A. Hendrick, "Positive antimitochondrial antibody but normal alkaline phosphatase: is this primary biliary cirrhosis?" Hepatology, vol. 6, no. 6, pp. 1279-1284, 1986.

[123] M. I. Prince, A. Chetwynd, W. L. Craig, J. V. Metcalf, and O. F. W. James, "Asymptomatic primary biliary cirrhosis: clinical features, prognosis, and symptom progression in a large population based cohort," Gut, vol. 53, no. 6, pp. 865$870,2004$.

[124] C. Corpechot, A. El Naggar, A. Poujol-Robert et al., "Assessment of biliary fibrosis by transient elastography in patients with PBC and PSC," Hepatology, vol. 43, no. 5, pp. 11181124, 2006.

[125] D. Roulot, J. L. Costes, J. F. Buyck et al., "Transient elastography as a screening tool for liver fibrosis and cirrhosis in a community-based population aged over 45 years," Gut, 2010.

[126] M. Nakamura, H. Kondo, T. Mori et al., "Anti-gp210 and anti-centromere antibodies are different risk factors for the progression of primary biliary cirrhosis," Hepatology, vol. 45, no. 1, pp. 118-127, 2007.

[127] P. Caramaschi, D. Biasi, T. Manzo, A. Carletto, F. Poli, and L. M. Bambara, "Anticentromere antibody-clinical associations. A study of 44 patients," Rheumatology International, vol. 14, no. 6, pp. 253-255, 1995.

[128] G. Spencer-Green, D. Alter, and H. G. Welch, "Test performance in systemic sclerosis: anti-centromere and anti-Scl-70 antibodies," American Journal of Medicine, vol. 103, no. 3, pp. 242-248, 1997.

[129] J. Avouac, J. Fransen, U. A. Walker et al., "Preliminary criteria for the very early diagnosis of systemic sclerosis: results of a
Delphi consensus study from EULAR scleroderma trials and research group," Annals of the Rheumatic Diseases, vol. 70, no. 3, pp. 476-481, 2011.

[130] B. Marasini, C. Pipia, G. DeValle et al., "Vascular impairment in patients with primary biliary cirrhosis," International Journal of Microcirculation, Clinical and Experimental, vol. 15, no. 2, pp. 75-79, 1995.

[131] V. Fonollosa, C. P. Simeón, L. Castells et al., "Morphologic capillary changes and manifestations of connective tissue diseases in patients with primary biliary cirrhosis," Lupus, vol. 10, no. 9, pp. 628-631, 2001.

[132] M. Juárez, R. Misischia, and G. S. Alarcón, "Infections in systemic connective tissue diseases: systemic lupus erythematosus, scleroderma, and polymyositis/dermatomyositis," Rheumatic Disease Clinics of North America, vol. 29, no. 1, pp. 163-184, 2003.

[133] M. Abu-Shakra and P. Lee, "Mortality in systemic sclerosis: a comparison with the general population," Journal of Rheumatology, vol. 22, no. 11, pp. 2100-2102, 1995.

[134] C. Bryan, Y. Howard, P. Brennan, C. Black, and A. Silman, "Survival following the onset of scleroderma: results from a retrospective inception cohort study of the UK population," British Journal of Rheumatology, vol. 35, no. 11, pp. 11221126, 1996.

[135] H. Jackson, M. Solaymani-Dodaran, T. R. Card, G. P. Aithal, R. Logan, and J. West, "Influence of ursodeoxycholic acid on the mortality and malignancy associated with primary biliary cirrhosis: a population-based cohort study," Hepatology, vol. 46, no. 4, pp. 1131-1137, 2007.

[136] S. Jacobsen, P. Halberg, and S. Ullman, "Mortality and causes of death of 344 Danish patients with systemic sclerosis (scleroderma)," British Journal of Rheumatology, vol. 37, no. 7, pp. 750-755, 1998.

[137] T. C. Mahl, W. Shockcor, and J. L. Boyer, "Primary biliary cirrhosis: survival of a large cohort of symptomatic and asymptomatic patients followed for 24 years," Journal of Hepatology, vol. 20, no. 6, pp. 707-713, 1994.

[138] H. C. Mitchison, M. R. Lucey, P. J. Kelly, J. M. Neuberger, R. Williams, and O. F. W. James, "Symptom development and prognosis in primary biliary cirrhosis: a study in two centers," Gastroenterology, vol. 99, no. 3, pp. 778-784, 1990.

[139] R. P. Myers, A. A. M. Shaheen, A. Fong et al., "Epidemiology and natural history of primary biliary cirrhosis in a Canadian Health Region: a population-based study," Hepatology, vol. 50, no. 6, pp. 1884-1892, 2009.

[140] A. J. Tyndall, B. Bannert, M. Vonk et al., "Causes and risk factors for death in systemic sclerosis: a study from the EULAR Scleroderma Trials and Research (EUSTAR) database," Annals of the Rheumatic Diseases, vol. 69, no. 10, pp. 1809-1815, 2010.

[141] D. E. Jones, A. Al-Rifai, J. Frith, I. Patanwala, and J. L. Newton, "The independent effects of fatigue and UDCA therapy on mortality in primary biliary cirrhosis: results of a 9 year follow-up," Journal of Hepatology, vol. 53, no. 5, pp. 911-917, 2010.

[142] C. Pollak, E. Minar, B. Dragosics, and L. Marosi, "Primary biliary cirrhosis and sclerodermia: long term benign course of a complex autoimmune disease," Leber Magen Darm, vol. 15, no. 2, pp. 85-89, 1985.

[143] D. R. Beswick, G. Klatskin, and J. L. Boyer, "Asymptomatic primary biliary cirrhosis. A progress report on long-term follow-up and natural history," Gastroenterology, vol. 89, no. 2, pp. 267-271, 1985. 
[144] U. Beuers, "Drug insight: mechanisms and sites of action of ursodeoxycholic acid in cholestasis," Nature Clinical Practice Gastroenterology and Hepatology, vol. 3, no. 6, pp. 318-328, 2006.

[145] B. Combes, R. L. Carithers, W. C. Maddrey et al., "A randomized, double-blind, placebo-controlled trial of ursodeoxycholic acid in primary biliary cirrhosis," Hepatology, vol. 22, no. 3, pp. 759-766, 1995.

[146] E. J. Heathcote, K. Cauch-Dudek, V. Walker et al., "The Canadian multicenter double-blind randomized controlled trial of ursodeoxycholic acid in primary biliary cirrhosis," Hepatology, vol. 19, no. 5, pp. 1149-1156, 1994.

[147] K. D. Lindor, E. R. Dickson, W. P. Baldus et al., "Ursodeoxycholic acid in the treatment of primary biliary cirrhosis," Gastroenterology, vol. 106, no. 5, pp. 1284-1290, 1994.

[148] A. Parés, L. Caballería, J. Rodés et al., "Long-term effects of ursodeoxycholic acid in primary biliary cirrhosis: results of a double-blind controlled multicentric trial. UDCA-Cooperative Group from the Spanish Association for the Study of the Liver," Journal of Hepatology, vol. 32, no. 4, pp. 561566, 2000.

[149] R. E. Poupon, B. Balkau, E. Eschwege, and R. Poupon, "A multicenter, controlled trial of ursodiol for the treatment of primary biliary cirrhosis. UDCA-PBC Study Group," The New England Journal of Medicine, vol. 324, no. 22, pp. 15481554, 1991.

[150] J. Goulis, G. Leandro, and A. K. Burroughs, "Randomised controlled trials of ursodeoxychoric-acid therapy for primary biliary cirrhosis: a meta-analysis," The Lancet, vol. 354, no. 9184, pp. 1053-1060, 1999.

[151] C. Corpechot, L. Abenavoli, N. Rabahi et al., "Biochemical response to ursodeoxycholic acid and long-term prognosis in primary biliary cirrhosis," Hepatology, vol. 48, no. 3, pp. 871877, 2008.

[152] A. Parés, L. Caballería, and J. Rodés, "Excellent longterm survival in patients with primary biliary cirrhosis and biochemical response to ursodeoxycholic acid," Gastroenterology, vol. 130, no. 3, pp. 715-720, 2006.

[153] J. Avouac, O. Kowal-Bielecka, R. Landewe et al., "European League Against Rheumatism (EULAR) Scleroderma Trial and Research group (EUSTAR) recommendations for the treatment of systemic sclerosis: methods of elaboration and results of systematic literature research," Annals of the Rheumatic Diseases, vol. 68, no. 5, pp. 629-634, 2009.

[154] O. Kowal-Bielecka, R. Landewé, J. Avouac et al., "EULAR recommendations for the treatment of systemic sclerosis: a report from the EULAR Scleroderma Trials and Research group (EUSTAR)," Annals of the Rheumatic Diseases, vol. 68, no. 5, pp. 620-628, 2009.

[155] L. J. Rubin, D. B. Badesch, R. J. Barst et al., "Bosentan therapy for pulmonary arterial hypertension," The New England Journal of Medicine, vol. 346, no. 12, pp. 896-903, 2002. 


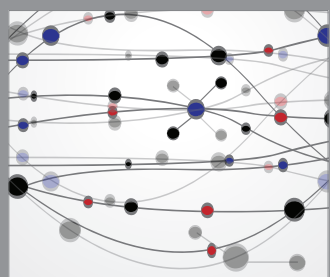

The Scientific World Journal
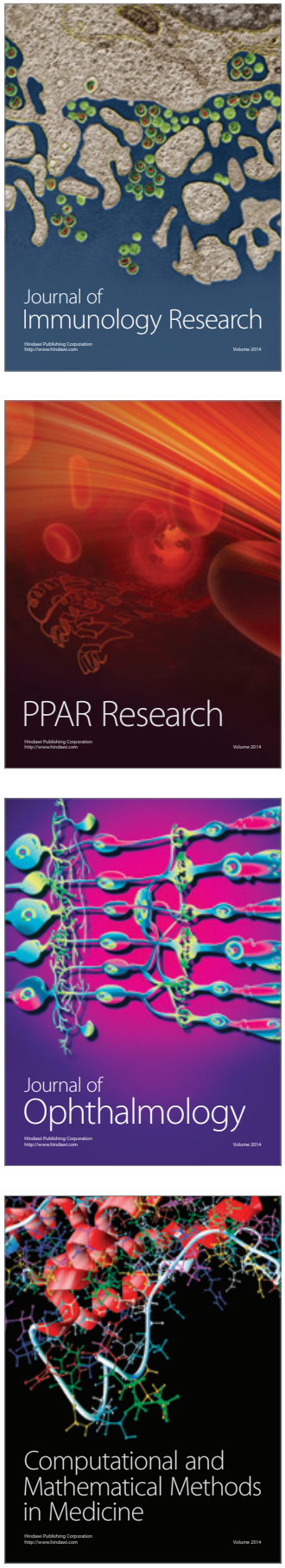

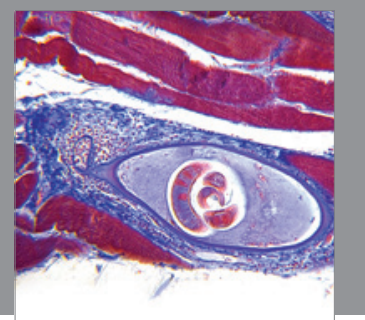

Gastroenterology

Research and Practice
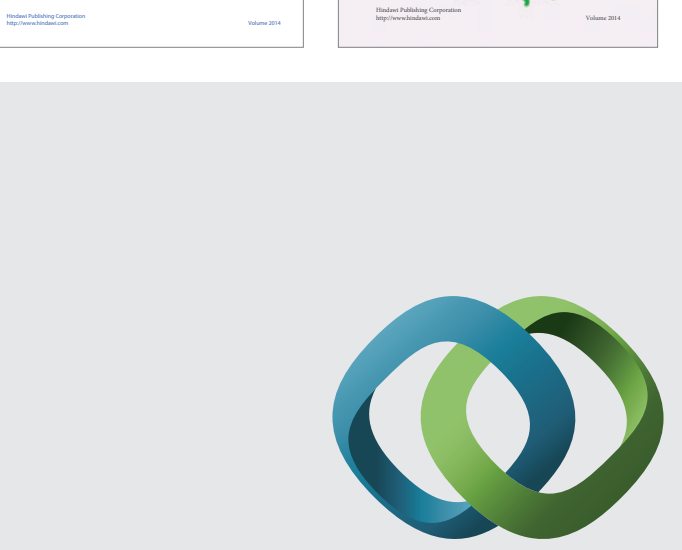

\section{Hindawi}

Submit your manuscripts at

http://www.hindawi.com
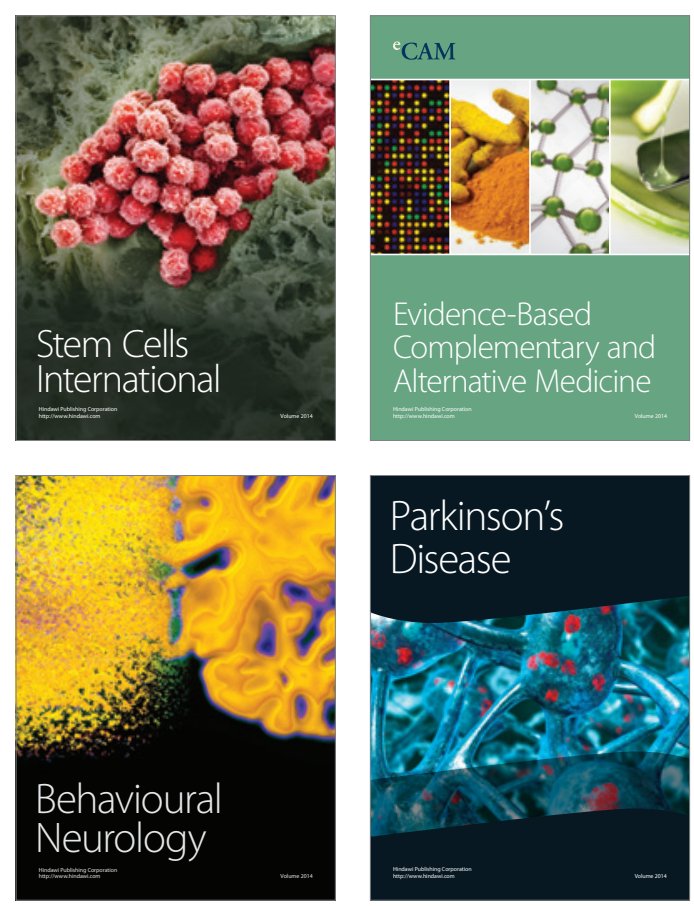

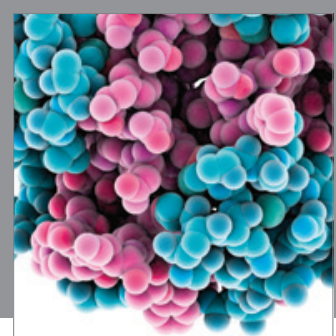

Journal of
Diabetes Research

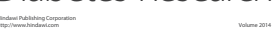

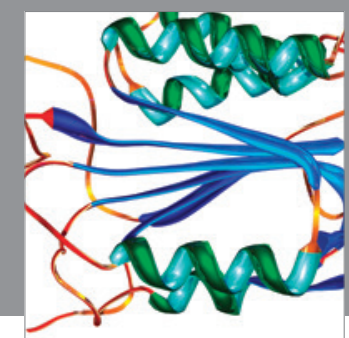

Disease Markers
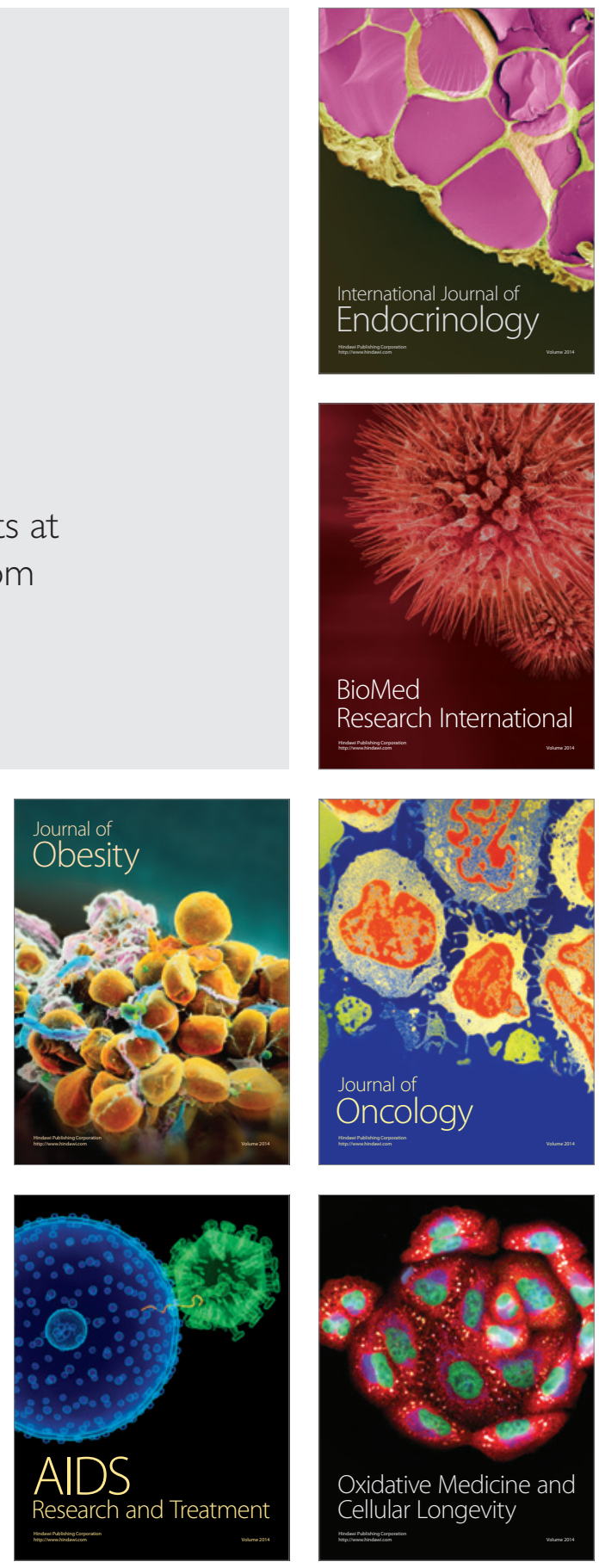